\title{
Warfarin: Is the end nigh? Please?
}

\section{RF Neilson}

Consultant Haematologist, Forth Valley Royal Hospital, Larbert, Stirlingshire, UK

AUTHORS Connolly SJ, Ezekowitz MD, Yusuf S et al.

TITLE Dabigatran versus warfarin in patients with atrial fibrillation

JOURNAL N Engl J Med 2009; 36I:I |39-5I. doi:I0.1056/NEJMoa090556I

DECLARATION OF INTERESTS No conflict of interests declared.

\begin{abstract}
Correspondence to RF Neilson, Department of Haematology, Forth Valley Royal Hospital, Stirling Road, Larbert, Stirlingshire FK5 4WR, UK
\end{abstract}

tel. $+44(0) / 324566000$

e-mail roderick.neilson@nhs.net

\section{SUMMARY}

This paper reports the results of the RE-LY (Randomized Evaluation of Long-Term Anticoagulation Therapy) Trial. In this trial, more than 18,000 patients with atrial fibrillation (AF) and high risk of stroke based on age, previous stroke or transient ischaemic attack or heart failure were assigned to receive, in a blinded arm, the oral direct thrombin inhibitor dabigatran in a dose of either $110 \mathrm{mg}$ or $150 \mathrm{mg}$ twice daily or, in an unblinded arm, adjusted-dose warfarin. The primary outcome measured was the rate of stroke or systemic embolism.

Rates of the primary outcome were $1.69 \%$ per year in the warfarin group, compared with $1.53 \%$ per year in the group on $110 \mathrm{mg}$ of dabigatran and $1.11 \%$ per year in the group on $150 \mathrm{mg}$ of dabigatran. The major bleeding rate was $3.36 \%$ per year in the warfarin group, compared with $2.71 \%$ per year in the group receiving $110 \mathrm{mg}$ of dabigatran. The rate of haemorrhagic stroke was $0.38 \%$ per year in the warfarin group, compared with $0.12 \%$ per year in the $110 \mathrm{mg}$ of dabigatran group. The mortality rate was $4.13 \%$ per year in the warfarin group, compared with $3.75 \%$ per year with $110 \mathrm{mg}$ of dabigatran.

This shows that dabigatran in a dose of $110 \mathrm{mg}$ twice daily is as effective in reducing the risk of arterial embolic events as warfarin but with a lower risk of major haemorrhage. The $150 \mathrm{mg}$ twice-daily dose of dabigatran is associated with a lower risk of arterial embolic events than warfarin but with similar rates of haemorrhage. It confirms that modern oral anticoagulant agents are as effective as warfarin with fewer problems with bleeding and no requirement for laboratory monitoring.

\section{DISCUSSION}

There can be very few doctors who are happy with warfarin as an anticoagulant. From problems with dosing due to multiple interactions with food and drugs, to the infrastructure required to monitor its use and the almost daily problems with patients being over- or under-anticoagulated due to its narrow therapeutic window, its use has been tolerated as it is cheap and, until recently, there were no effective oral alternatives. This has now changed. The development of oral agents that inhibit specific factors in the coagulation mechanism, specifically Factor $X a$ and thrombin, and which do not require laboratory monitoring, has been a holy grail of anticoagulant therapy. All a new antithrombotic agent had to prove was that it was as good as warfarin, with a wider therapeutic window and with fewer adverse effects, especially haemorrhage.

This has not been an easy path. An early contender, ximelagatran, showed itself to be an effective anticoagulant but in 2004 failed to gain US Food and Drug Administration approval due to hepatic toxicity.' In addition, the development of new anticoagulant agents has shown itself to be more stepwise than linear, and follows the paradigm set out by Turpie et al..$^{2,3}$ where agents are often first evaluated for prevention of venous thromboembolism (VTE) after major orthopaedic surgery, with small numbers of patients needed to show an effect and short duration of therapy, through VTE treatment studies and then stroke prevention studies in AF, where the duration of therapy is often long and the numbers of patients needed to show a significant effect is large.

The current state of play with these agents reflects this. The oral thrombin inhibitor dabigatran and the anti $\mathrm{Xa}$ agent rivaroxaban have been licensed and approved for use for venous thromboprophylaxis in knee and hip joint replacement surgery following trial. Dabigatran is currently undergoing appraisal by the National Institute for Health and Clinical Excellence for use in the prevention of stroke in patients with AF. Rivaroxaban is being studied in various clinical settings, including treatment of acute deep vein thrombosis (ODIXa-DVT and EINSTEIN-DVT studies), in AF (ROCKET-AF Study) and in VTE prophylaxis in hospitalised medical patients (MAGELLAN Study). ${ }^{3}$

Some questions remain about the new oral agents, including their safety in patients with hepatic impairment; comparisons between $\mathrm{Xa}$ inhibitors and the thrombin 
inhibitors where the $\mathrm{Xa}$ inhibitors may be safer and more effective; and, finally, the cost of these new agents compared with warfarin. ${ }^{4}$ However, if warfarin was a newly developed drug the chances of it being approved or licensed for use in the 2 Ist century would be as high as the survival profile of a snowball in hell. The newer agents have shown themselves to be as effective, and certainly no less safe, than warfarin. Is it too much to hope for that the days of warfarin, with all the clinical misery surrounding its use, are coming to an end?

\section{REFERENCES}

I Brinker A, He R, Desai M et al. Safety of ximelagatran. JAMA 2005; 293:2859. doi:10.100I/jama.293.23.2859-a

2 Turpie AG, Lassen MR, Davidson BL et al. Rivaroxaban versus enoxaparin for thromboprophylaxis after total knee arthroplasty (RECORD4): a randomised trial. Lancet 2009; 373:1673-80.

3 Turpie AG. New oral anticoagulants in atrial fibrillation. Eur Heart J 2008; 29:155-65. doi:10.1093/eurheartj/ehm575

4 Raju NC, Hankey GJ. Dabigatran etexilate in people with atrial fibrillation. BMJ 2010; 341:c3784. doi:10.1 I36/bmj.c3784 doi: $10.1016 / 50140-6736(09) 60734-0$

\section{Exclusive offer for RCPE Collegiate Members $\mathbf{5 0 \%}$ discount on Fellowship subscriptions}

We are pleased to offer a significant discount in annual subscription rates for eligible Collegiate Members who are Consultants and wish to progress to Fellowship. ${ }^{*}$ Collegiate Members of four years' standing who are successful in their nomination for Fellowship will be able to obtain a $50 \%$ discount on their first year's Fellowship subscription and a $25 \%$ reduction on their second year's subscription, offering savings of up to $£ 300$.

Please access details of our reduced subscription rates, including concessionary elements for Fellows working less than halftime or on maternity leave, at: www.rcpe.ac.uk/join/ fellowshipoffer.php

\section{Fellowship confers a range of additional benefits and opportunities:}

- International peer and public recognition through the use of the 'FRCP Edin' postnominals.

- Professional support for revalidation/ recertification.

- The opportunity to participate in projects and working groups to determine the future direction of education and clinical medicine.

- The opportunity to help maintain national and international clinical standards by acting as an MRCP(UK) examiner.

- The opportunity to inform College responses to external policy consultations in your specialty.

- The opportunity to participate in the governance of the College through election to committees and to Council.

\footnotetext{
*Eligible candidates should normally have held a substantive Consultant post or equivalent for at least 11 months. If you hold such a post and are interested in being considered for Fellowship, the principal method is nomination by an existing Fellow. Please e-mail Avril Harries at a.harries@rcpe.ac.uk for a list of Fellows in your area. Alternatively, you may wish to discuss nomination with one of our Regional Advisers or consider self-nomination.
} 